\title{
Prognostic significance of serum hepatocyte growth fac- tor in clear cell renal cell carcinoma : comparison with serum vascular endothelial growth factor
}

\author{
Shuji Tanimoto', Tomoharu Fukumori², Gad El-Moula², Avirmed Shiirevnyamba², \\ Shinichiro Kinouchi², Takahiro Koizumi ${ }^{2}$, Ryoichi Nakanishi', Yasuyo Yamamoto², \\ Ryuichi Taue ${ }^{2}$, KunihisaYamaguchi ${ }^{2}$, Hiroyoshi Nakatsuji ${ }^{2}$, Tomoteru Kishimoto², \\ Hirofumi Izaki ${ }^{2}$, Natsuo Oka², Masayuki Takahashi², and Hiro-omi Kanayama² \\ ${ }^{1}$ Department of Urology, Takamatsu Red Cross Hospital, Takamatsu, Japan; and ${ }^{2}$ Department of \\ Urology, Institute of Health Biosciences, The University of Tokushima Graduate School, Tokushima, \\ Japan
}

\begin{abstract}
No adequate serum predictive biomarker currently exists, which can identify the activity of renal cell carcinoma (RCC). We investigate the association of serum hepatocyte growth factor (HGF) and serum vascular endothelial growth factor (VEGF) levels with clinicopathologic parameters in untreated clear cell RCC patients. We measured serum levels of HGF and VEGF in 45 patients with untreated clear cell RCC and 45 healthy controls using an enzyme-linked immunosorbent assay (ELISA). Patients with clear cell RCC had significantly higher serum HGF and VEGF concentrations than healthy subjects : median, 1070.7 versus $728.3 \mathrm{pg} / \mathrm{ml}(\mathrm{p}<0.0001)$ for HGF ; and median, 397.5 versus $245.6 \mathrm{pg} / \mathrm{ml}(\mathrm{p}=0.0003$ ) for VEGF. We found a significant correlation between serum level of HGF and clinical stage and tumor grade. Survival of patients with high serum HGF ( $>1150 \mathrm{pg} / \mathrm{ml}$ ) was significantly reduced compared to patients with low serum HGF concentrations $(p=0.0044)$. In patients with nuclear grade 2 or high stage $R C C$, the higher serum HGF group exhibited significantly lower cause-specific survival $(p=$ 0.0087 and $p<0.05$, respectively). No significant difference was observed between serum VEGF levels and cause-specific survival rate. Serum HGF might be a diagnostic and prognostic indicator in clear cell RCC, especially for patients with grade 2 or high stage RCC. J. Med. Invest. 55 : 106-111, February, 2008
\end{abstract}

Keywords : renal cell carcinoma, hepatocyte growth factor, vascular endothelial growth factor, prognostic maker, diagnostic maker

\section{INTRODUCTION}

Renal cell carcinoma (RCC) is the most common

Received for publication November 19, 2007 ; accepted December 25, 2007.

Address correspondence and reprint requests to Dr. Hiro-omi Kanayama, Department of Urology, Institute of Health Biosciences, The University of Tokushima Graduate School, Kuramoto-cho, Tokushima 770-8503, Japan and Fax : +81-88-633-7160. malignant tumor that arises from the kidney. Fiveyear survival rates for patients with tumors confined to the kidney range from $60 \%$ to $90 \%(1,2)$. Once RCC has metastasized, the 5-year survival rate is less than $10 \%$ (3). The main prognostic indicator in $\mathrm{RCC}$ patients is clinical stage, and the presence or absence of metastasis at the time of diagnosis remains the main factor in determining survival (4). Tumor nuclear grade and histologic features such as 
cell type carry only limited prognostic value $(5,6)$. Consequently, a need exists for additional diagnostic and prognostic markers to identify the activity of RCC.

Recent studies show that angiogenesis plays an important role in the growth, progression, and metastasis of solid tumors (7). Several factors have been identified which enhance angiogenesis, such as basic fibroblast growth factor (b-FGF) and vascular endothelial growth factor (VEGF) $(8,9)$. Increased circulating levels of b-FGF and VEGF have been reported in renal cell carcinoma patients $(10$, 11). More recently, many observations have indicated that hepatocyte growth factor (HGF) is also a powerful inducer of angiogenesis $(12,13)$.

HGF is a stromal cell-derived cytokine involved in cell proliferation, tissue regeneration, tumor growth and tumor invasion (14-17). The role of HGF in tumor biology has been supported by immunohistochemical studies in various human carcinomas, including RCC $(18,19)$. Recent studies have shown that HGF and its receptor, c-MET, play a significant role in the progression of $\operatorname{RCC}(20,21)$. Positive correlation between $\mathrm{HGF} /$ Met expression levels of RCC tissue and tumor progression has been shown $(20,21)$. To our knowledge, there exists a lack of quantitative data comparing the serum concentration of HGF to clinicopathological findings and clinical outcome in RCC patients.

In the present report, we examined the serum levels of HGF and VEGF, which are strong angiogenic factors, in 45 patients with clear cell RCC and 45 healthy individuals, using an enzyme-linked immunosorbent assay (ELISA). We investigated the correlation of serum HGF levels with clinicopathological parameters and compared the diagnostic and prognostic value of serum HGF with serum VEGF in clear cell RCC patients.

\section{MATERIALS AND METHODS}

We analyzed pretreatment serum HGF and VEGF concentrations from 45 patients with clear cell RCC admitted to the Department of Urology, The University Hospital of Tokushima School of Medicine, Japan. Of these patients, 27 were male and 18 were female with a mean age of 61.5 years (range 23 to 81 years). Patients with a renal tumor that was histologically different from clear cell RCC were excluded because a phenotype of RCC was quite different based on the histological subtypes. Moreover, we excluded the patients with evidence of other cancer, recent trauma or surgery, pregnancy, and hepatitis to avoid the possibility of elevated serum HGF and VEGF concentrations. The serum samples were collected before nephrectomy or other treatments such as chemotherapy or interferon and/or interleukin-2 (IL-2) immunotherapy. Tumors were staged according to the TNM staging classification of the International Union Against Cancer (22). Staging procedures included physical examination, chest radiography, ultrasonography, and computerized tomography. If caval invasion was suspected, magnetic resonant scanning was performed. $\mathrm{Pa}$ tients with elevated serum alkaline phosphates or skeletal symptoms were assessed by bone scintigraphy and radiography. As shown in Table 1, the patients were staged as follows : 11 stage I, 18 stage II, 5 stage III, and 11 stage IV. Twenty-nine patients had low stage cancer (stage I and II), and 16 patients had high stage cancer (stage III and IV). Tumor nuclear grading was performed according to the 1997 TNM grading system (22). The grade distribution was as follows : 14 grade 1,26 grade 2 , and five grade 3 tumors. Follow-up ranged 4.9 to 109.0 months (average 38.6 months).

Informed consent was obtained from all the subjects, and the study protocol was approved by the ethics committee.

Table 1 Summary of the characteristics of 45 patients with clear cell renal cell carcinoma

\begin{tabular}{lc}
\hline Characters & No. of patients \\
\hline Age & \\
23-81 yrs (mean, 61.5 yrs) & \\
Sex & 27 \\
Male & 18 \\
Female & \\
Clinical stage & 11 \\
I & 18 \\
II & 5 \\
III & 11 \\
IV & \\
Histologic grade (G) & 14 \\
G1 & 26 \\
G2 & 5 \\
G3 & \\
Follow-up period & \\
$4.9-109.0$ mos (median, 38.6 mos) & \\
\hline
\end{tabular}




\section{Controls}

Blood samples were obtained from the peripheral veins of 45 subjects with no evidence of disease, such as inflammatory disease or other cancers. The subjects included 32 men and 13 women with a mean age of 48.2 years (range 23 to 84 years). The absence of disease was assessed by clinical examination and routine laboratory tests.

\section{HGF and VEGF analysis}

Prior to treatment, a $10 \mathrm{~mL}$ clotted blood sample was taken, centrifused at $2000 \mathrm{rpm}$ for $10 \mathrm{~min}$ utes and a $1 \mathrm{~mL}$ aliquot of serum was then stored at $-80^{\circ} \mathrm{C}$ until analysis. The serum levels of HGF and VEGF were measured using sandwich enzyme immunoassay methods (Quantikine, R\&D systems, Minneapolis, MN). We tested each samples at least in duplicate and repeated an experiment three times.

\section{Statistical analysis}

Distribution of serum HGF between different groups was compared using the Mann-Whitney-U test. Survival curves were estimated using the KaplanMeier method, and survival times were compared by the log-rank test. Survival time was measured from date of diagnosis to date of death or last followup. Sensitivity and specificity were calculated from the receiver-operating-characteristics (ROC) curve. Statistical significance was concluded based on $\mathrm{p}<$ 0.05 as a minimum level.

\section{RESULTS}

Serum HGF concentrations ranged from 416.7 to $1037.3 \mathrm{pg} / \mathrm{ml}$ (median $728.3 \mathrm{pg} / \mathrm{ml}$ ), and serum VEGF concentrations ranged from 11.3 to $921.7 \mathrm{pg} /$ $\mathrm{ml}$ (median $245.6 \mathrm{pg} / \mathrm{ml}$ ) in the presumably healthy individuals (Table 2). There was no difference in gender between RCC group and healthy controls, but patients with clear cell RCC was older than health individuals (data not shown). However, there is no significant correlation in serum HGF and VEGF levels with gender and age.

A significant correlation was found between absolute HGF and VEGF serum levels ( $n=45$; $r=$ $0.570 ; \mathrm{p}<0.001$ ) (Fig. 1). HGF and VEGF blood levels were significantly higher in the 45 patients with RCC than in the 45 healthy controls (HGF, median 1070.7 in RCC patients versus $728.3 \mathrm{pg} / \mathrm{ml}$ in healthy controls, $\mathrm{p}<0.0001$; VEGF, median 397.5 in RCC patients versus $245.6 \mathrm{pg} / \mathrm{ml}$ in healthy controls, $\mathrm{p}=0.0003)$. Serum HGF levels were significantly higher in patients with high stage RCC than in those with low stage cancer (median 1252.9 versus $948.7 \mathrm{pg} / \mathrm{ml}, \mathrm{p}=0.0044)$, in patients with high grade (grade 2 and 3 ) cancer than in those with grade 1 cancer (median 1163.4 versus 845.8 pg/ml, $\mathrm{p}=0.0419$ ), in patients with distant metastasis than in those without distant metastasis (median 1375.0 versus $836.6 \mathrm{pg} / \mathrm{ml}, \mathrm{p}=0.0014)$. No significant differences were observed between serum VEGF levels and stage (median 397.5 for low stage versus

Table 2 Levels of serum HGF in healthy controls and patients with clear cell renal cell carcinoma

\begin{tabular}{|c|c|c|c|c|c|c|c|}
\hline \multirow[b]{2}{*}{ Group } & \multirow[b]{2}{*}{ No. of patients } & \multicolumn{3}{|c|}{$\mathrm{HGF}(\mathrm{pg} / \mathrm{ml})$} & \multicolumn{3}{|c|}{ VEGF (pg/ml) } \\
\hline & & Median & Range & $P$ value & Median & Range & $\mathrm{P}$ value \\
\hline Healthy individuals & 45 & 728.3 & 416.7-1037.3 & $\mathrm{p}<0.0001^{\mathrm{a}}$ & 245.6 & $11.3-921.7$ & $\mathrm{p}=0.0003^{\mathrm{a}}$ \\
\hline Clear cell renal cancer & 45 & 1070.7 & $412.6-2572.0$ & & 397.5 & $99.3-1256.3$ & \\
\hline Low stage (I+II) & 29 & 948.7 & $453.6-1539.0$ & $\mathrm{p}=0.0044^{\mathrm{b}}$ & 397.5 & $113.2-984.7$ & $\mathrm{p}=0.7579$ \\
\hline High stage (III+IV) & 16 & 1252.9 & $412.6-2572.0$ & & 383.4 & $99.3-1256.3$ & \\
\hline Non-Metastatic (M0) & 34 & 836.6 & $453.6-1539.0$ & $\mathrm{p}=0.0014^{\mathrm{c}}$ & 293.7 & $113.2-984.7$ & $\mathrm{p}=0.061$ \\
\hline Metastatic (M1) & 11 & 1375.0 & $412.6-2572.0$ & & 412.1 & $99.3-1256.3$ & \\
\hline Low grade (G1) & 14 & 845.8 & $453.6-1200.5$ & $\mathrm{p}=0.0419^{\mathrm{d}}$ & 290.0 & $113.2-500.0$ & $\mathrm{p}=0.0607$ \\
\hline High grade $(\mathrm{G} 2+3)$ & 31 & 1163.4 & $412.6-2572.0$ & & 412.1 & $99.3-1256.3$ & \\
\hline
\end{tabular}

a $\mathrm{P}$ value refers to the difference between the healthy controls and all patients with clear cell renal cancer.

b, c, d P values refer to the difference between the patients with low stage and high stage RCC or between the patients with distant metastasis and without distant metastasis, or between the patients with low grade and high grade RCC. 


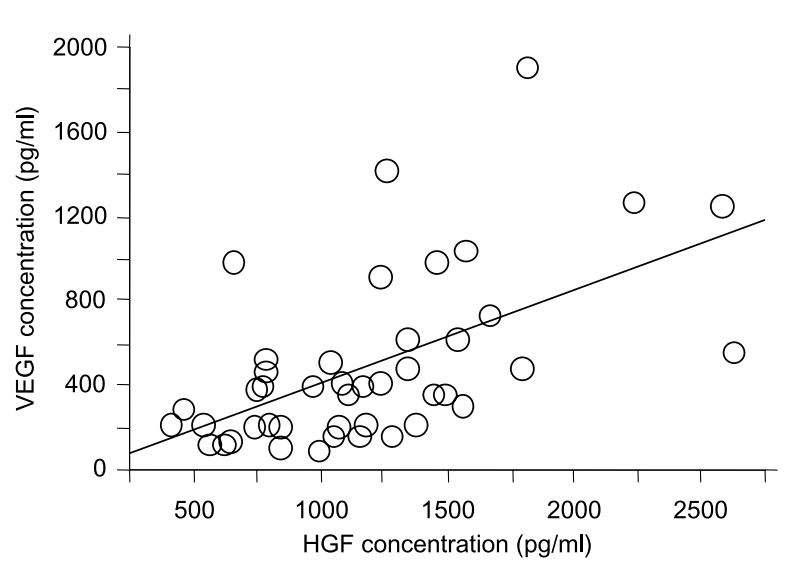

Fig. 1 Correlation of serum HGF and VEGF levels in 45 patients with clear cell renal cell carcinoma. Each dot represents the HGF and VEGF serum level of one patient (simple linear regression : $r=0.570 ; \mathrm{p}<0.001)$.

$383.4 \mathrm{pg} / \mathrm{ml}$ for high stage, $\mathrm{p}=0.7579$ ) or between serum VEGF levels and nuclear grade (median 290.0 for low grade versus $412.1 \mathrm{pg} / \mathrm{ml}$ for high grade, $\mathrm{p}=0.0607$ ) (Table 2 ). There was no difference between serum HGF and VEGF levels and tumor size (data not shown).

Patients with low stage RCC survived significantly longer than patients with high stage RCC $(\mathrm{p}=0.0008)$ (data not shown). Survival time of patients with high nuclear grade was significantly shorter than for those with low nuclear grade RCC $(p<0.05)$ (data not shown). Cutoff values of HGF and VEGF defined by ROC analysis were $1150 \mathrm{pg} /$ $\mathrm{ml}$ and $400 \mathrm{pg} / \mathrm{ml}$, respectively. The serum HGF cutoff value was most effective for differentiating the survival of patients in the current study. The sensitivity and specificity of serum HGF at the cutoff level of $1150 \mathrm{pg} / \mathrm{ml}$ were $85.7 \%$ and $57.8 \%$, respectively, and of serum VEGF at the cutoff level of $400 \mathrm{pg} / \mathrm{ml}, 85.7 \%$ and $46.7 \%$, respectively. Patients with serum HGF levels above the cutoff values exhibited significantly reduced survival compared to patients with lower values ( $\mathrm{p}=0.0044)$ (Fig. 2). No significant difference was observed between serum VEGF level and cause-specific survival rate (data not shown).

In patients with the grade $2 \mathrm{RCC}$, six of 12 patients in the higher serum HGF subgroup $(\geqq 1150$ $\mathrm{pg} / \mathrm{ml}$ ) died of RCC, whereas only one of $14 \mathrm{pa}-$ tients in the lower serum HGF subgroup $(<1150$ $\mathrm{pg} / \mathrm{ml}$ ) died of RCC. Figure 3A shows that the higher serum HGF subgroup in patients with grade 2 RCC exhibited significantly lower cause-specific survival $(p=0.0087)$. Figure $3 B$ indicates that in the

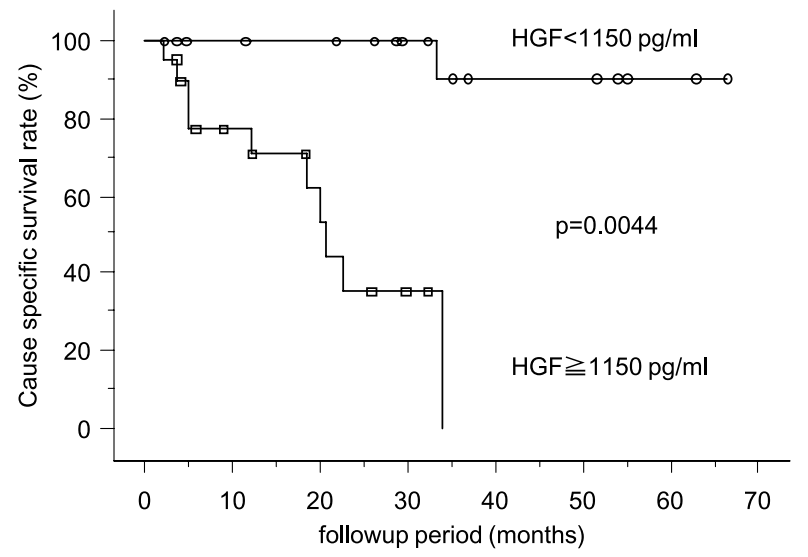

Fig. 2 Kaplan-Meier cause-specific survival curves according to serum levels of HGF.

A Grade 2

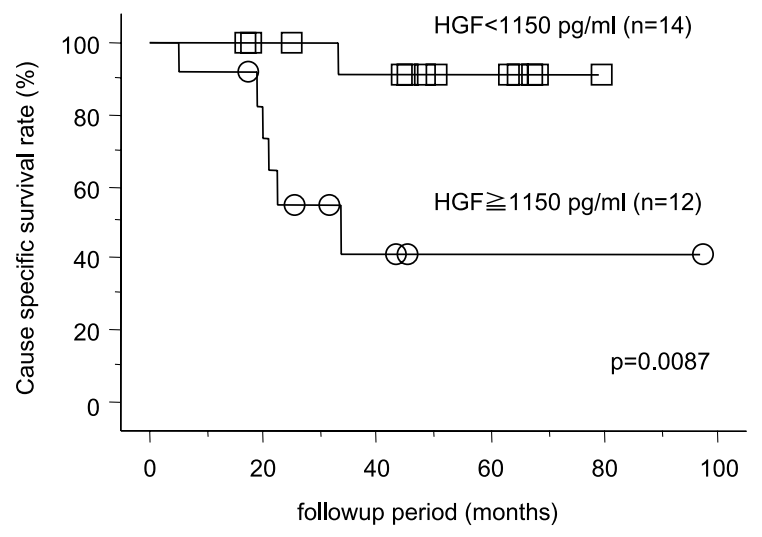

B High stage (stage II I and IV)

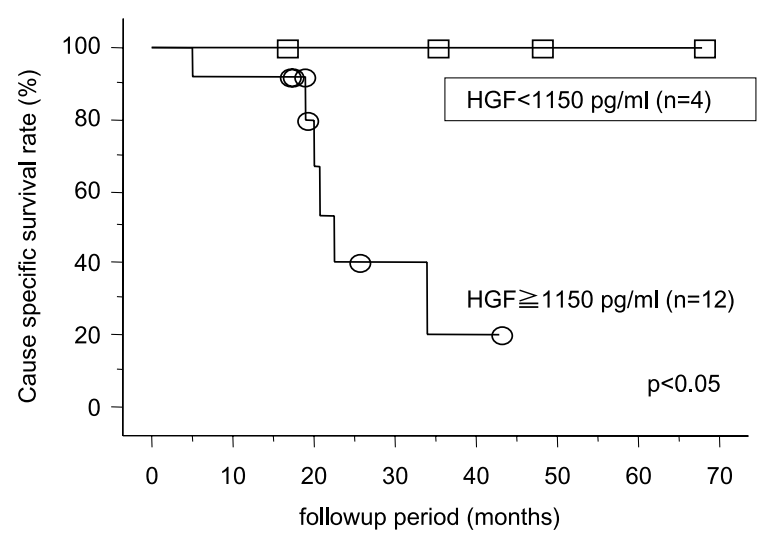

Fig. 3 Kaplan-Meier cause-specific survival curves according to serum levels of HGF in patients with grade 2 tumors (A) and with high stage (stage III and IV) tumors (B).

cases with high stage tumors (stage III and IV), the higher serum HGF subgroup also had significantly lower cause-specific survival $(\mathrm{p}<0.05)$. No significant differences were observed between serum VEGF levels and cause-specific survival rate in grade 2 
RCC $(\mathrm{p}=0.4906)$ or in high stage RCC $(\mathrm{p}=0.2278)$ (data not shown). There was no significant correlation between serum HGF levels and cause-specific survival rate in patients with grade 1 and grade 3 RCC.

\section{DISCUSSION AND CONCLUSIONS}

RCC is characterized by a lack of early warning signs, resulting in a high proportion of patients with metastasis at diagnosis or relapse following nephrectomy. RCC is also known for its unpredictable clinical behavior. Progression of metastasis can occur many years after surgery on the primary tumor, or spontaneous regression of distant metastasis is observed $(23,24)$. A need exists for prognostic factors that identify the subsets of RCC patients with low versus high risk at the time of diagnosis. Recently, it has been suggested that one of the angiogenic factors, hepatocyte growth factor (HGF), plays an important role in tumor progression and angiogenesis of RCC $(18,20,21)$. Several studies have implicated the involvement of HGF and its receptor MET signaling in the oncogenesis of RCC (18, $20,21)$. Nevertheless, the biological significance of serum HGF levels has not yet been fully clarified.

In the current study, we observed higher concentrations of serum HGF and VEGF in patients with cancer than individuals without RCC. Importantly, only serum HGF levels of high stage RCC patients were significantly higher than in low stage RCC patients. These results suggest that serum HGF is more useful as a diagnostic marker for screening of RCC than serum VEGF. Dosquet, et al. reported that serum HGF levels of nonmetastatic RCC patients was significantly higher than that of controls, but they found no correlation between serum HGF levels and tumor stage (10). In our study, serum HGF level increased with more advanced clinical stage and with higher nuclear grade. It was suggested that our exclusion of patients with potentially elevated serum HGF concentration due to other conditions diminished any sampling error.

Our recent results showed that serum HGF and VEGF levels were directly correlated with prognosis of clear cell RCC patients. Although it is dangerous to use arbitrary cutoffs to determine significance, a cutoff value of serum HGF $(1150 \mathrm{pg} / \mathrm{ml})$ and VEGF (300 pg/ml) defined by ROC analysis effectively differentiated the survival of the patients. Our data showed that both the higher serum HGF and VEGF subgroups had a significantly lower survival. In multivariate analysis, we found that both serum HGF and VEGF lost its prognostic information. A similar observation was noted in VEGF for RCC (11). This might depend on the sample numbers, follow-up periods, and the methods used for the analysis of HGF and VEGF expression. Prospective studies involving larger numbers of patients and longer follow-up periods are needed to confirm these findings.

In this study, we found the prognostic significance of serum HGF levels among patients with grade 2 $\mathrm{RCC}$. It is difficult to evaluate the biological aggressiveness of grade 2 tumors because grade 2 RCC remains heterogeneous. Therefore, it is important to differentiate high and low risk groups in the grade 2 RCC patients. Our results showed that the higher serum HGF group had significantly worse causespecific survival in grade $2 \mathrm{RCC}$ patients, though serum VEGF levels and tumor stage can not predict prognosis. Furthermore, in high stage tumors (stages III and IV), the higher serum HGF group also had significantly worse cause-specific survival. Serum HGF levels, but not VEGF levels can clinically differentiate patients with the grade 2 and high stage RCC into high and low risk, and is significantly correlated with prognosis and survival.

In conclusion, Serum HGF levels significantly correlated with tumor stage, histological grade, and prognosis of RCC. Our results indicate that serum levels of HGF can be useful as a diagnostic and prognostic marker for patients with untreated clear cell RCC. Although serum HGF did not remain an independent prognostic factor in multivariate analysis, serum HGF levels might be useful for the identification of patients with potentially progressive disease, especially for those with grade 2 and/or high stage RCC. Serum HGF may enhance the accuracy of conventional morphologic grading and pathologic staging systems in RCC patients. In this series, we evaluated pretreatment serum HGF concentrations in patients with clear cell RCC. In the future, it will be necessary to evaluate the post-therapeutic prognostic accuracy of serum HGF levels for therapy monitoring.

\section{REFERENCES}

1. Thompson IM, Peek $\mathrm{M}:$ Improvement in survival of patients with renal cell carcinoma- -the role of the serendipitously detected tumor, J 
Urol 140 : 487-490, 1988

2. Thrasher JB, Paulson DF : Prognostic factors in renal cancer. Urol Clin North Am 20 : 247262, 1993

3. Motzer RJ, Bander NH, Nanus DM : Renal-cell carcinoma. N Engl J Med 335 : 865-875, 1996

4. Strohmeyer T, Ackermann R : Classic and modern prognostic indicators in renal cell carcinoma. Review of the literature. Urol Int 47 : 203-212, 1991

5. Medeiros LJ, Gelb AB, Weiss LM : Renal cell carcinoma. Prognostic significance of morphologic parameters in 121 cases. Cancer 61 : 1639-1651, 1988

6. Fuhrman SA, Lasky LC, Limas C : Prognostic significance of morphologic parameters in renal cell carcinoma. Am J Surg Pathol 6 : 65563, 1982

7. Folkman J : Seminars in Medicine of the Beth Israel Hospital, Boston. Clinical applications of research on angiogenesis. N Engl J Med 333 : 1757-1763, 1995

8. D'Amato RJ, Loughnan MS, Flynn E, Folkman $\mathrm{J}$ : Thalidomide is an inhibitor of angiogenesis. Proc Natl Acad Sci USA 91 : 4082-5, 1994

9. Denekamp J : Review article : angiogenesis, neovascular proliferation and vascular pathophysiology as targets for cancer therapy. Br J Radiol 66 : 181-196, 1993

10. Dosquet C, Coudert MC, Lepage E, Cabane J, Richard F : Are angiogenic factors, cytokines, and soluble adhesion molecules prognostic factors in patients with renal cell carcinoma? Clin Cancer Res 3 : 2451-2458, 1997

11. Jacobsen J, Rasmuson T, Grankvist K, Ljungberg $\mathrm{B}$ : Vascular endothelial growth factor as prognostic factor in renal cell carcinoma. J Urol 163 : 343-347, 2000

12. Bussolino F, Di Renzo MF, Ziche M, Bocchietto E, Olivero M, Naldini L, Gaudino G, Tamagnone L, Coffer A, Comoglio PM : Hepatocyte growth factor is a potent angiogenic factor which stimulates endothelial cell motility and growth. J Cell Biol 119 : 629-641, 1992

13. Grant DS, Kleinman HK, Goldberg ID, Bhargava MM, Nickoloff BJ, Kinsella JL, Polverini $\mathrm{P}$, Rosen EM : Scatter factor induces blood vessel formation in vivo. Proc Natl Acad
Sci USA 90 : 1937-1941, 1993

14. Ho RT, Liew CT, Lai KN : The expression of hepatocyte growth factor (HGF) and interleukin 6 (IL-6) in damaged human liver and kidney tissues. Hepatogastroenterology 46 : 1904-1909, 1999

15. Igawa T, Matsumoto K, Kanda S, Saito $\mathrm{Y}$, Nakamura T: Hepatocyte growth factor may function as a renotropic factor for regeneration in rats with acute renal injury. Am J Physiol 265 : F61-69, 1993

16. Cantley LG, Barros EJ, Gandhi M, Rauchman M, Nigam SK : Regulation of mitogenesis, motogenesis, and tubulogenesis by hepatocyte growth factor in renal collecting duct cell. Am J Physiol 267 : F271-280, 1994

17. Bellusci S, Moens G, Gaudino G, Comoglio P, Nakamura T, Thiery JP, Jouanneau J : Creation of an hepatocyte growth factor/scatter factor autocrine loop in carcinoma cells induces invasive properties associated with increased tumorigenicity. Oncogene $9: 1091-9,1994$

18. Pisters LL, el-Naggar AK, Luo W, Malpica A, Lin SH : C-met proto-oncogene expression in benign and malignant human renal tissues. J Urol 158 : 724-248, 1997

19. Wagatsuma S, Konno R, Sato S, Yajima A : Tumor angiogenesis, hepatocyte growth factor, and c-Met expression in endometrial carcinoma. Cancer $82:$ 520-30, 1998

20. Horie S, Aruga S, Kawamata H, Okui N, Kakizoe T, Kitamura T: Biological role of HGF/MET pathway in renal cell carcinoma. J Urol 161 : 990-997, 1999

21. Natali PG, Prat M, Nicotra MR, Bigotti A, Olivero M, Comoglio PM, Di Renzo MF : Overexpression of the met/HGF receptor in renal cell carcinomas. Int J Cancer 69 : 212-217, 1996

22. Fleming ID : AJCC Cancer Staging Manual, 5th ed. Lippincott-Raven, Philadelphia, pp. 231232, 1997

23. Lokich J : Spontaneous regression of metastatic renal cancer. Case report and literature review. Am J Clin Oncol 20 : 416-418, 1997

24. Newmark JR, Newmark GM, Epstein JI, Marshall FF : Solitary late recurrence of renal cell carcinoma. Urology 43 : 725-728, 1994 